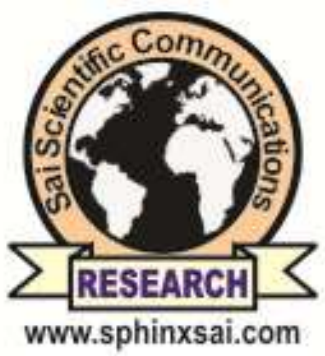

International Journal of PharmTech Research CODEN (USA): IJPRIF, ISSN: 0974-4304, ISSN(Online): 2455-9563

\title{
Fourier Transform Infrared Spectroscopy (FTIR) Analysis of Biodegradable Films Based On Modified Colombian Starches of Cassava and Yam
}

\author{
Torrenegra $M^{1,2,3}$, Solano $R^{1,2 \star}$, Herrera $A^{2}$, León $G^{1,2,3}$, Pajaro $A^{4}$ \\ ${ }^{1}$ Research Group on Biotechnology and Innovation (GIBEI). Center for Trade and \\ Services. Servicio Nacional de Aprendizaje (SENA). Cartagena-Colombia. \\ ${ }^{2}$ Nanomaterial and Computer Assisted Process Engineering. Faculty of Engineering, \\ University of Cartagena, Cartagena-Colombia. \\ ${ }^{3} \mathrm{PhD}$ student in Engineering. Faculty of Engineering, University of Cartagena, \\ Cartagena-Colombia. \\ ${ }^{4}$ Research Group on Processes of the Petrochemical Industry (GIPIPQ). Center for the \\ Petrochemical Industry. Servicio Nacional de Aprendizaje (SENA), Cartagena- \\ Colombia.
}

\begin{abstract}
Yams and other tubers such as potatoes, cassava and sweet potatoes represent crops of great economic importance worldwide, constituting the main source of income and employment in many rural areas of the world. In Colombia is important in the Caribbean coast the cultivation of these species type tubers, since there is concentrated $90 \%$ of the national production, mainly in 26 municipalities belonging to the departments of Sucre, Córdoba and Bolívar. There are some identified by the Secretary of agriculture the agricultural sector of Bolivar factors that impede its accelerated development and improvements in competitive terms, within which are the poor infrastructure, especially in irrigation and tertiary pathways, weak direct rural technical assistance and low capacity of producers to generate revenue because of the limited market that have their harvested products. For this reason, is required to expand the use of native tubers (cassava, sweet potato and Yam) in other industrial sectors, to increase demand and favor the growth of the Department's agricultural sector. In the present investigation proposes the use of native starches as raw material in the production of food packaging, which were modified chemically by reaction of hydrolysis and esterification (DDSA, OSA and AA). Starches and films based on native and modified starches were characterized by FTIR spectroscopy and the results revealed that employed reactions can add hydrophobic functional groups to improve the water resistance of the biodegradable films based on starches.
\end{abstract}

Keywords : Cassava,Sweet potato,films, chemical modification, starch.

Solano R A. et al /International Journal of PharmTech Research, 2018,11(4): 368-376.

DOI: http://dx.doi.org/10.20902/IJPTR.2018.11408 


\section{Introduction}

Inside the Department of Bolivar, with greater production of Yam municipalities are El Carmen de Bolívar 70.800 tonnes in 2014, followed by San Juan Nepomuceno $(14,040)$ and San Jacinto $(4,200)$, while in municipalities such as María La Baja, Mahates, Villanueva, San Estanislao, Calamar and Cartagena, the production of name occurs to a lesser extent. As far as the production of cassava is concerned, the municipalities of greater production are Mahates with 84,000 tonnes in 2014, followed by El Carmen de Bolívar $(4,200)$, Arjona $(43,194)$, San Juan Nepomuceno $(21,600)$ and Villanueva $(13,000)$. In the light of the before mentioned statistical data comes a terrifying problem associated with the overproduction of these tubers in the Department, and particularly in the Montes de Maria ${ }^{1}$.The problem concerning the lack of market for the marketing of native tubers in the Caribbean region requires the attention of the national and international scientific community, so it is necessary to investigate in the utilization of the biomass in other productive sectors, allowing its economic expansion from the generation of added value. Unfortunately, the problems aren't the only one that is intended to deal with through the implementation of the proposed research project. Today, the market of foodstuffs requires to meet the needs of the world's population. They are also demanded safe, nutritious and less perishable, as well as high-quality ${ }^{2}$. Therefore, many efforts focus on the development of specific packaging, with mechanical, optical, and anti-microbial to ensure the comprehensive quality of the product $^{3}$.

In the present investigation were biodegradable films through the Casting technique based on modified starches from manioc and Yam by reactions of hydrolysis and esterification with dodecenil succinicanhydride (DDSA), octenil succinic anhydride (OSA) and acetic anhydride (AA). Finally, the obtained films were characterized by FTIR spectroscopy to verify the success of the modification.

\section{Experimental}

\section{Materials}

Cassava (Manihot esculenta) and Yam (Dioscorea rotundata) were collected from San Juan Nepomuceno, Colombia. 2-Dodecen-1-yl succinic anhydride (95\%), 2-Octen-1-yl succinic anhydride (97\%), Acetic anhydride ( $\geq 98 \%)$ and hydrochloric acid (37\%) were purchased from Sigma-Aldrich. All reactions were carried out using ACS Reagent chemicals.

\section{Starch Modification}

Partial acid hydrolysis process is outlined in Figure 1, which was performed based on recent research of Bet et al. ${ }^{4}$, Jeong et al. ${ }^{5}$, Dai et al. ${ }^{6}$ and Chen et al. ${ }^{7}$. On the other hand, the processes of esterification with DDSA, OSA and AA, were made through published methodologies for Sun et al. ${ }^{8}$, Fonseca et al. ${ }^{9}$ and Shah et al. ${ }^{10}$, respectably, as summarized in Figure 2 .

\section{Films preparation and characterization}

Films based on native or modified starches preparation process is shown in Figure 3, through the methodology similar to that developed by Oleyaei et al. ${ }^{11}$. Finally, the obtained films were stored in sealed bags to its characterization. The FTIR spectroscopy of starches and films were made on using a SHIMADZU IRTracer-100 spectrophotometerin the spectral range of 400 and $4000 \mathrm{~cm}^{-1}$. 


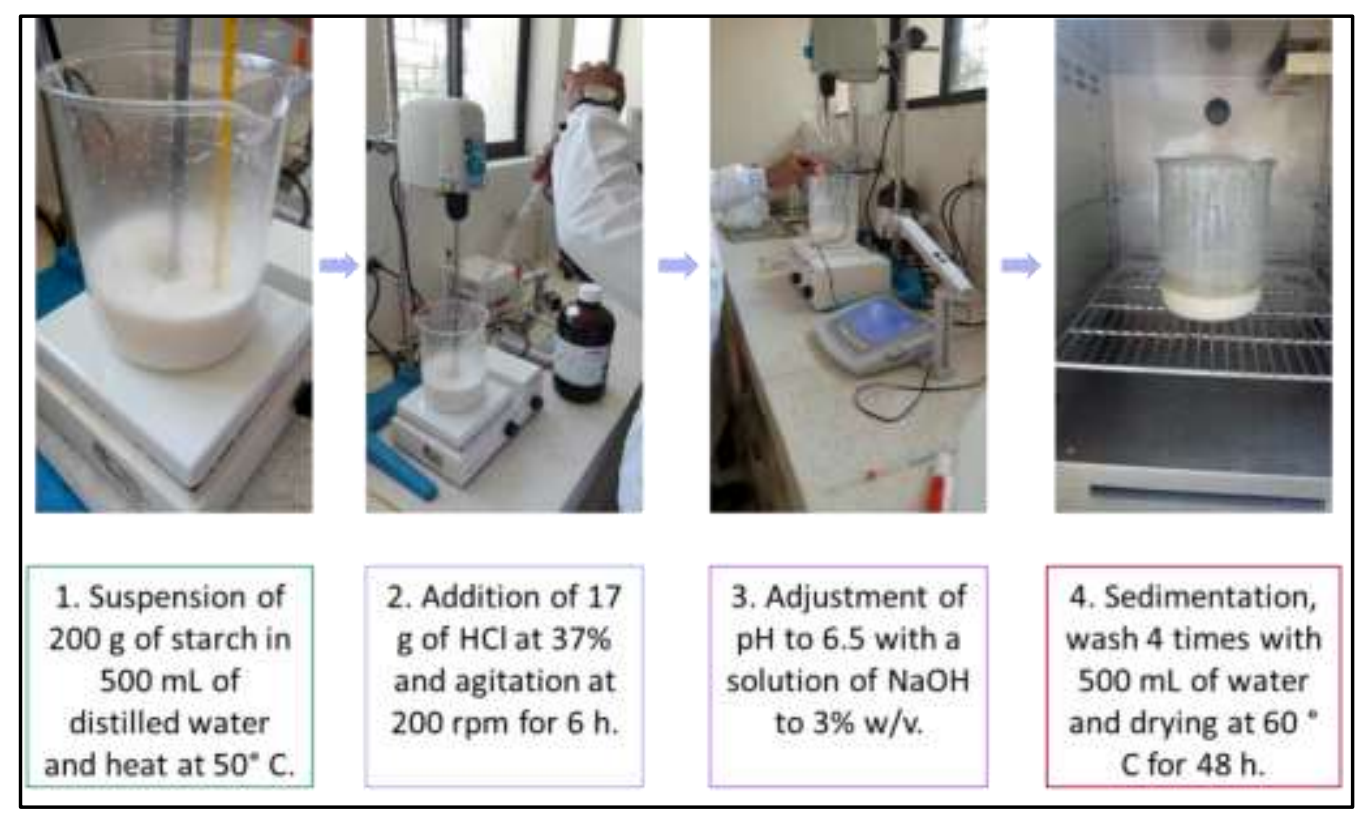

Figure 1. Partial acid hydrolysis procces.

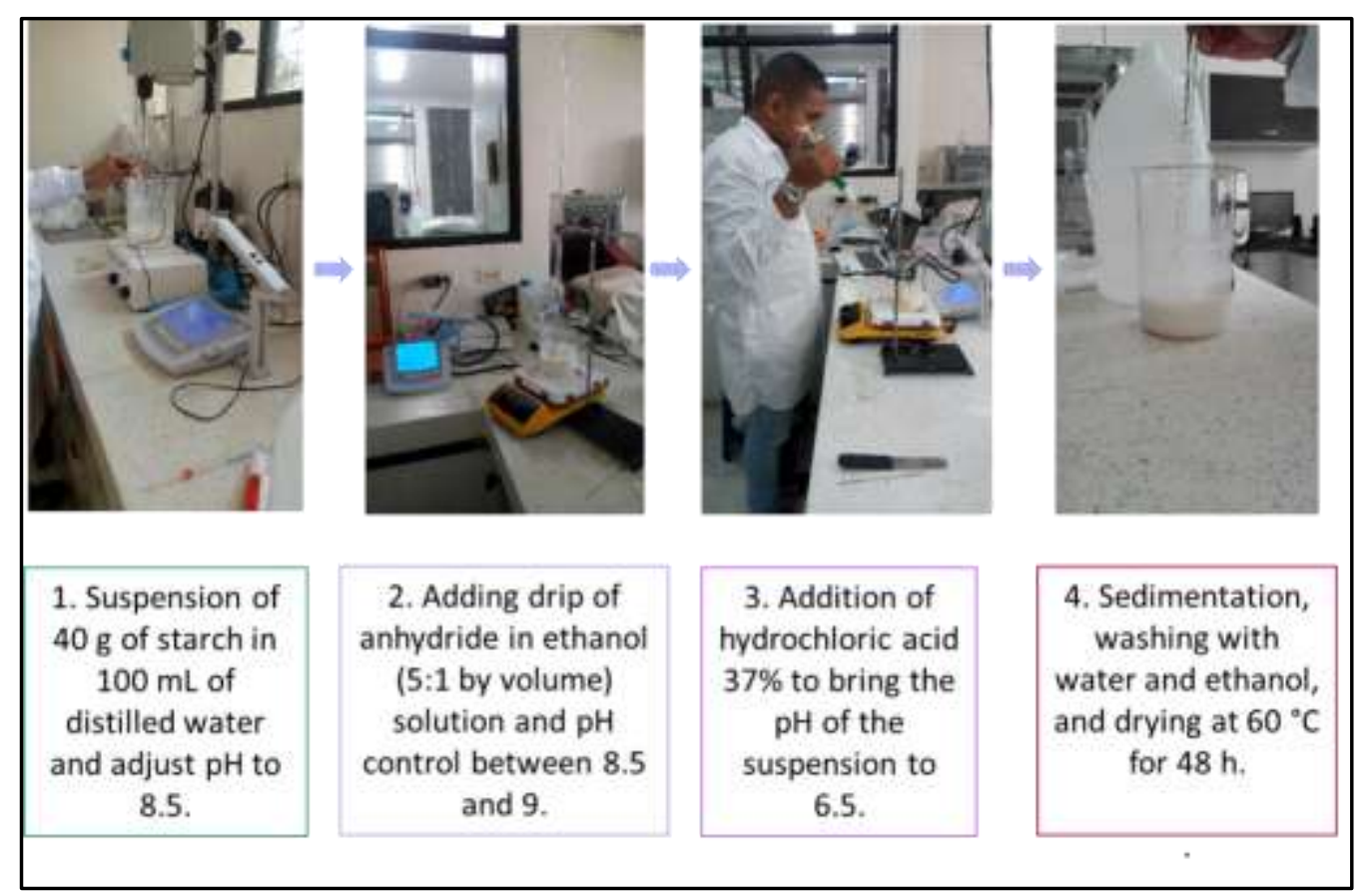

Figure 2. Process of esterification with DDSA, OSA and AA. 


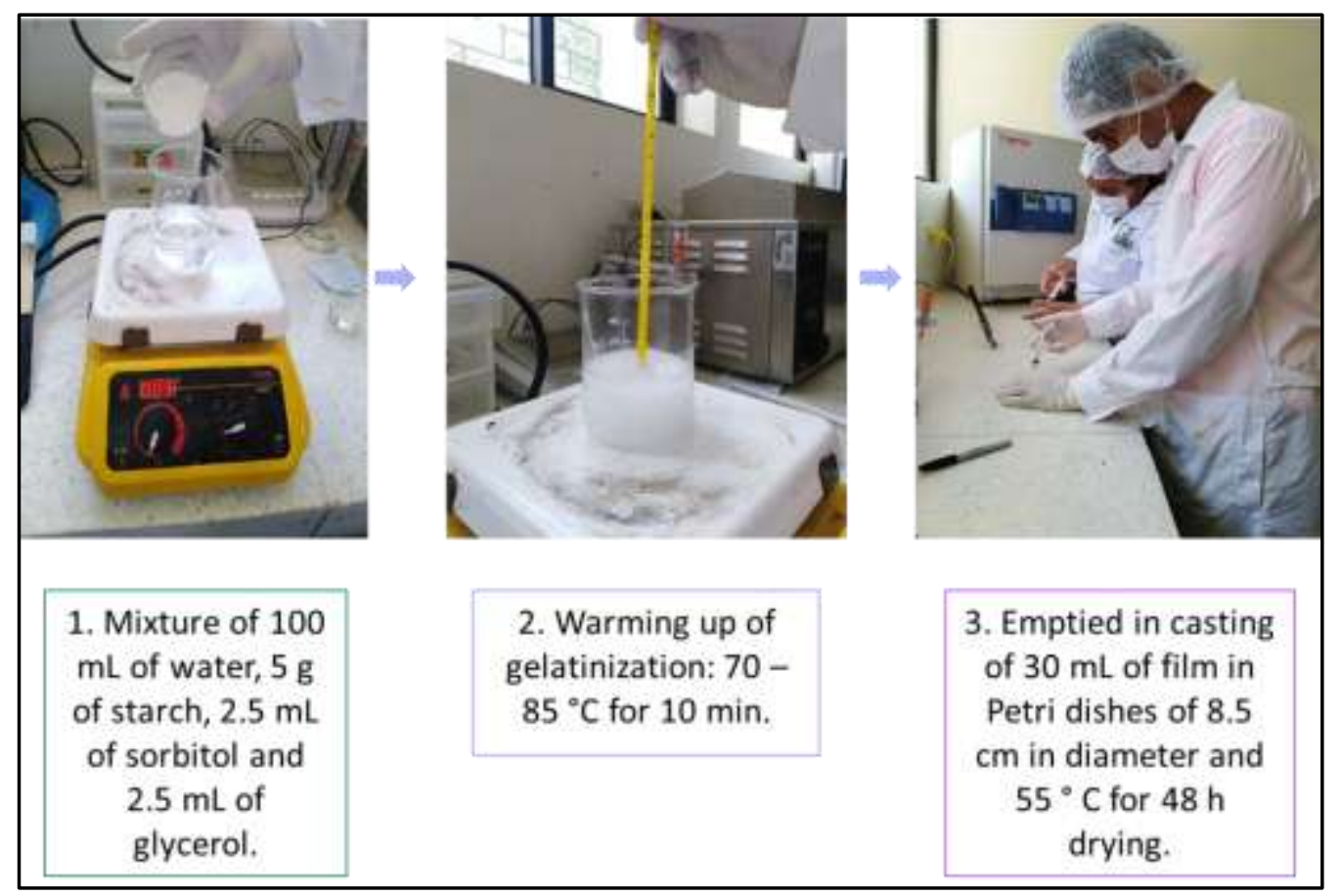

Figure 3. Process of films preparation.

\section{Results and discussion}

\section{FTIR spectroscopy}

The FTIR spectra of the modified starches from manioc and Yam are shown in Figure 4 and Figure 5, respectively. In addition, the FTIR spectra of films based on modified starches from manioc and Yam are shown in Figure 6 and Figure 7, respectively. The film based on cassava starch esterified with acetic anhydride could not be prepared due to the high hydrophobicity of starch, which prevents the gelatinizing process. Table 1 summarizes the most relevant information of the bands found in the FTIR spectra of starches and their respective biofilms. Also, are supported with recently published literature.

Table 1. Bands found in the FTIR spectra of starches and their respective biofilms.

\begin{tabular}{|l|l|l|}
\hline Band $\left(\mathbf{c m}^{-1}\right)$ & Comment & Reference \\
\hline 3300 & $\mathrm{O}-\mathrm{H}$ stretching vibration & {$[12]$} \\
\hline 2947 & $-\mathrm{CH}_{2}$ stretchingvibrational modes & {$[13]$} \\
\hline 1740 & $\begin{array}{l}\text { carbonyl }(\mathrm{C}=\mathrm{O}) \text { stretching vibration (only for esterified } \\
\text { starches with DDSA, OSA and AA) }\end{array}$ & {$[14]$} \\
\hline 1690 & Angular O-H bendingof water molecules & {$[15]$} \\
\hline 1152 & Anti-symmetric stretching of the C-O-C & {$[16]$} \\
\hline 1080 & Stretching vibration of the C-O & {$[17]$} \\
\hline 1010 & Anhydroglucose ring O-C stretch & {$[18]$} \\
\hline
\end{tabular}



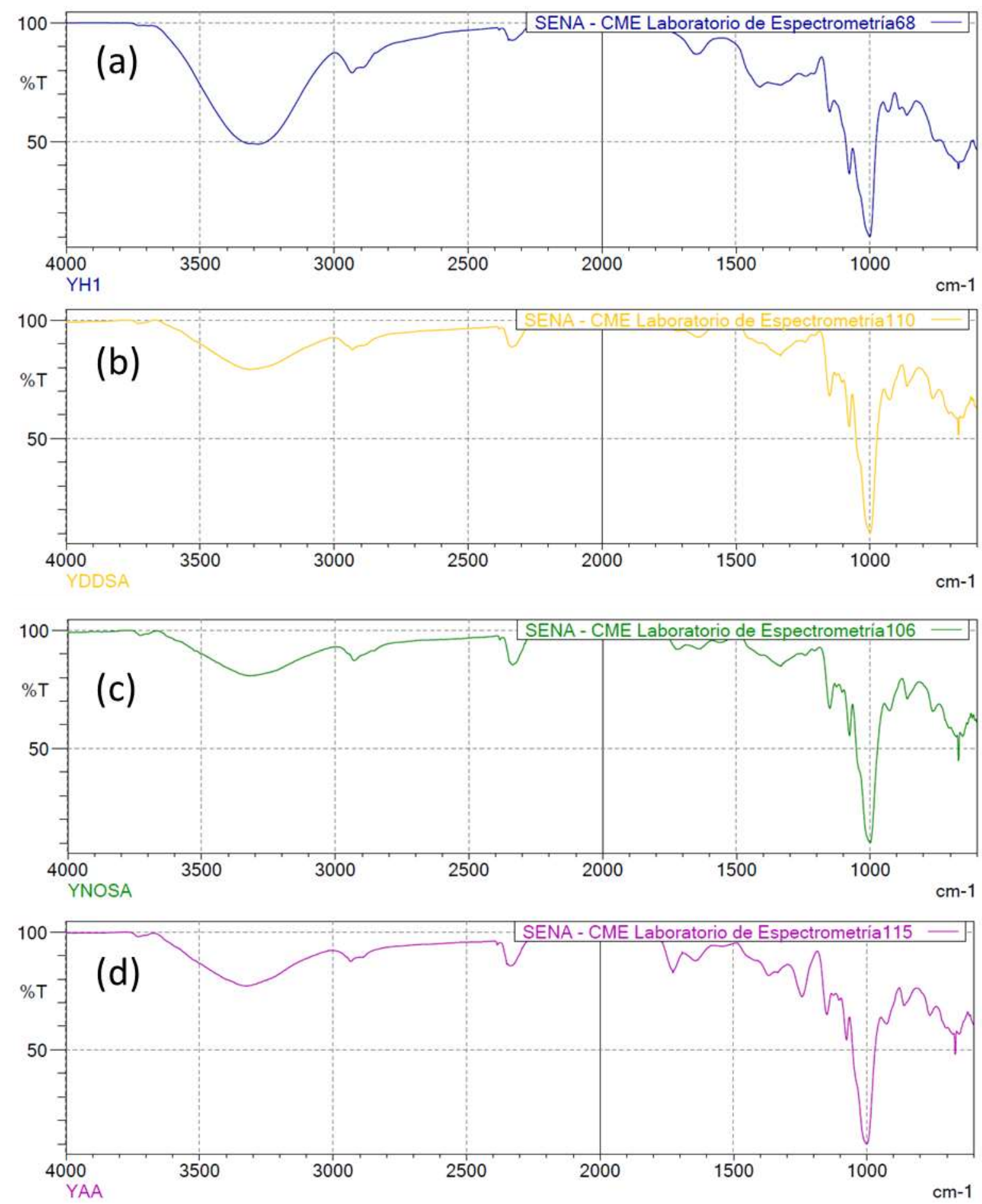

Figure 4. FTIR spectra of Cassava starch: (a) hydrolyzed, (b) esterified with DDSA, (c) esterified with OSA and (d) esterified AA. 

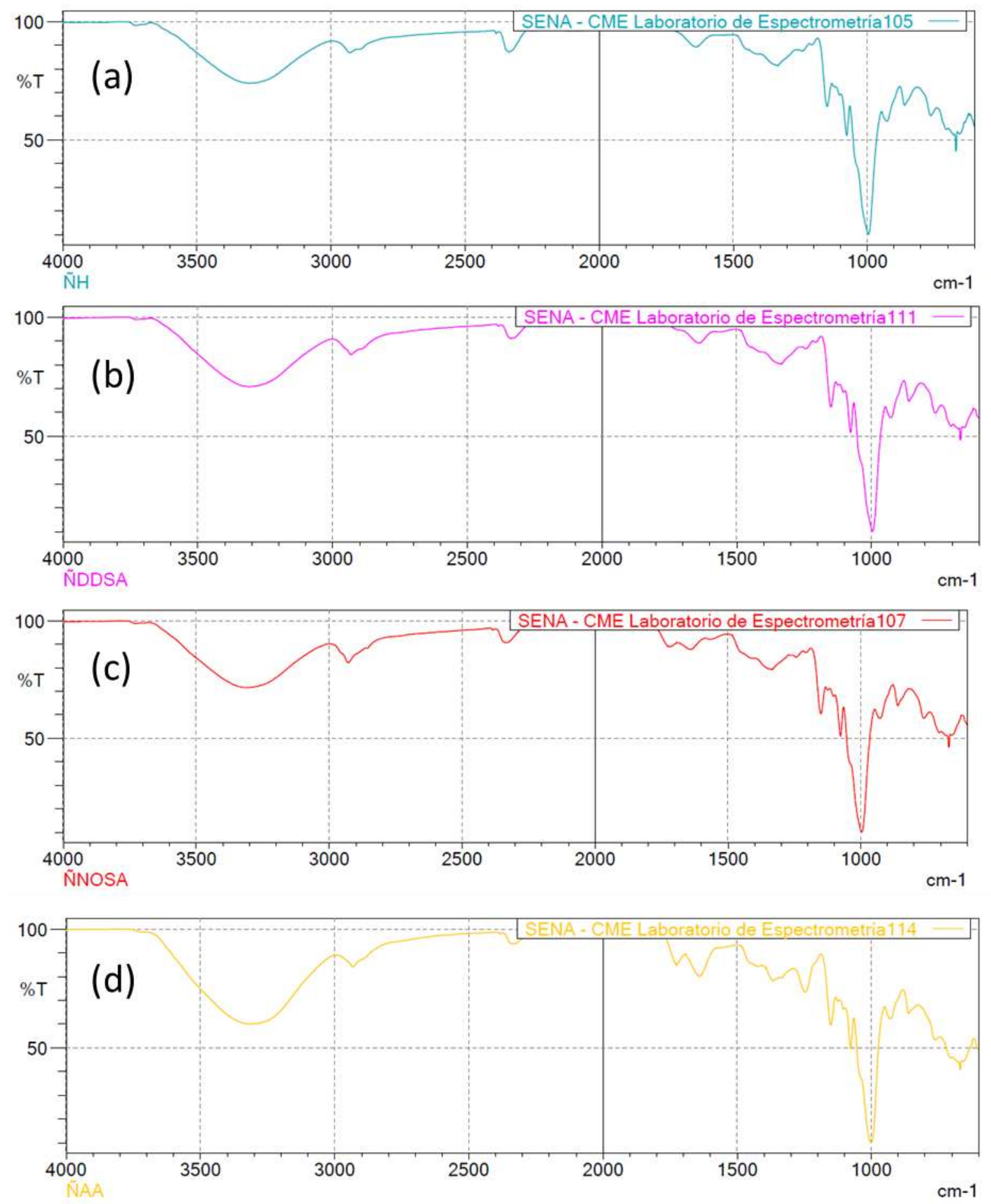

Figure 5. FTIR spectra ofYam starch: (a) hydrolyzed, (b) esterified with DDSA, (c) esterified with OSA and (d) esterified AA. 

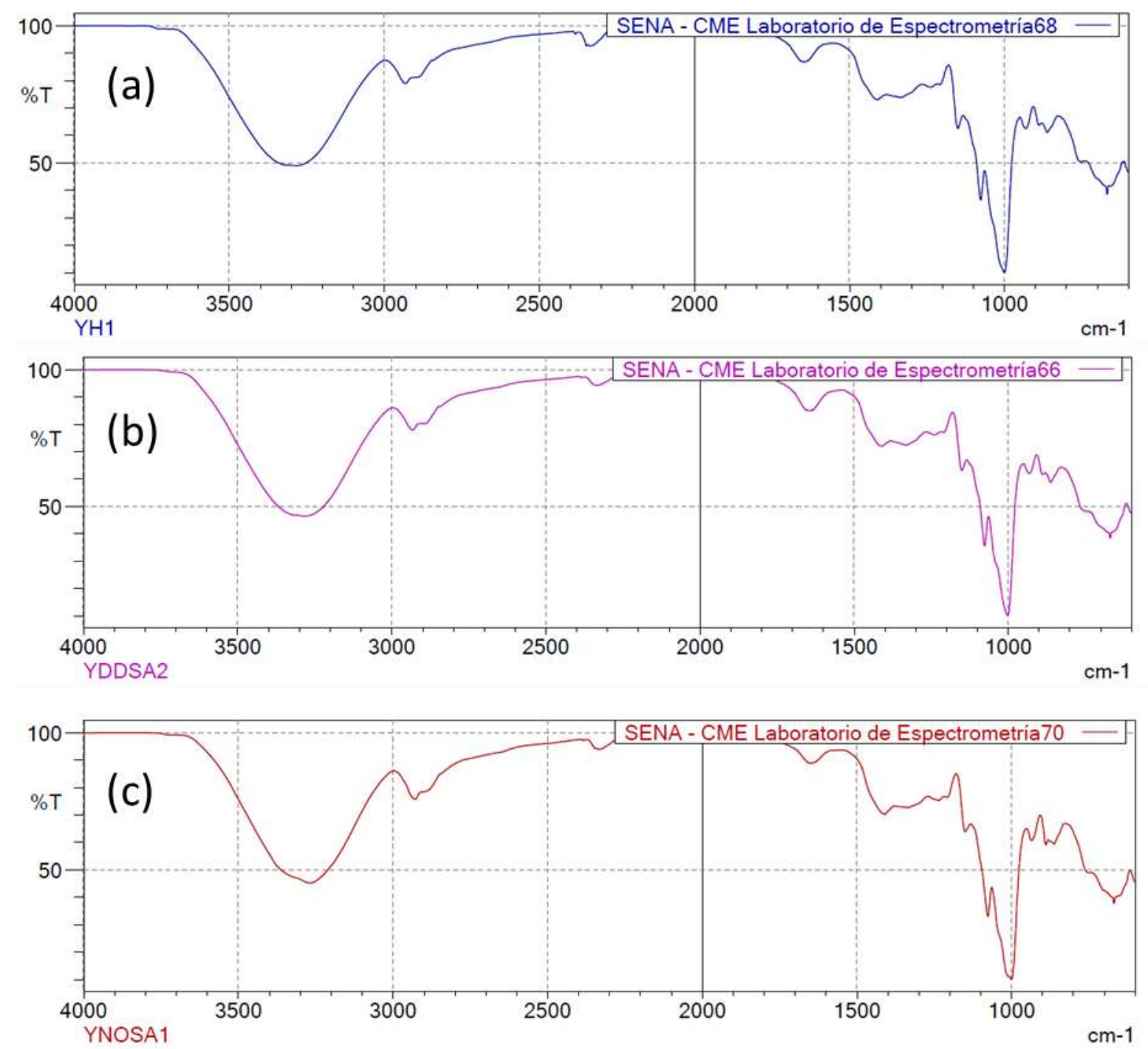

Figure 6. FTIR spectra of films based on Cassava starch: (a) hydrolyzed, (b) esterified with DDSA and (c) esterified with OSA. 

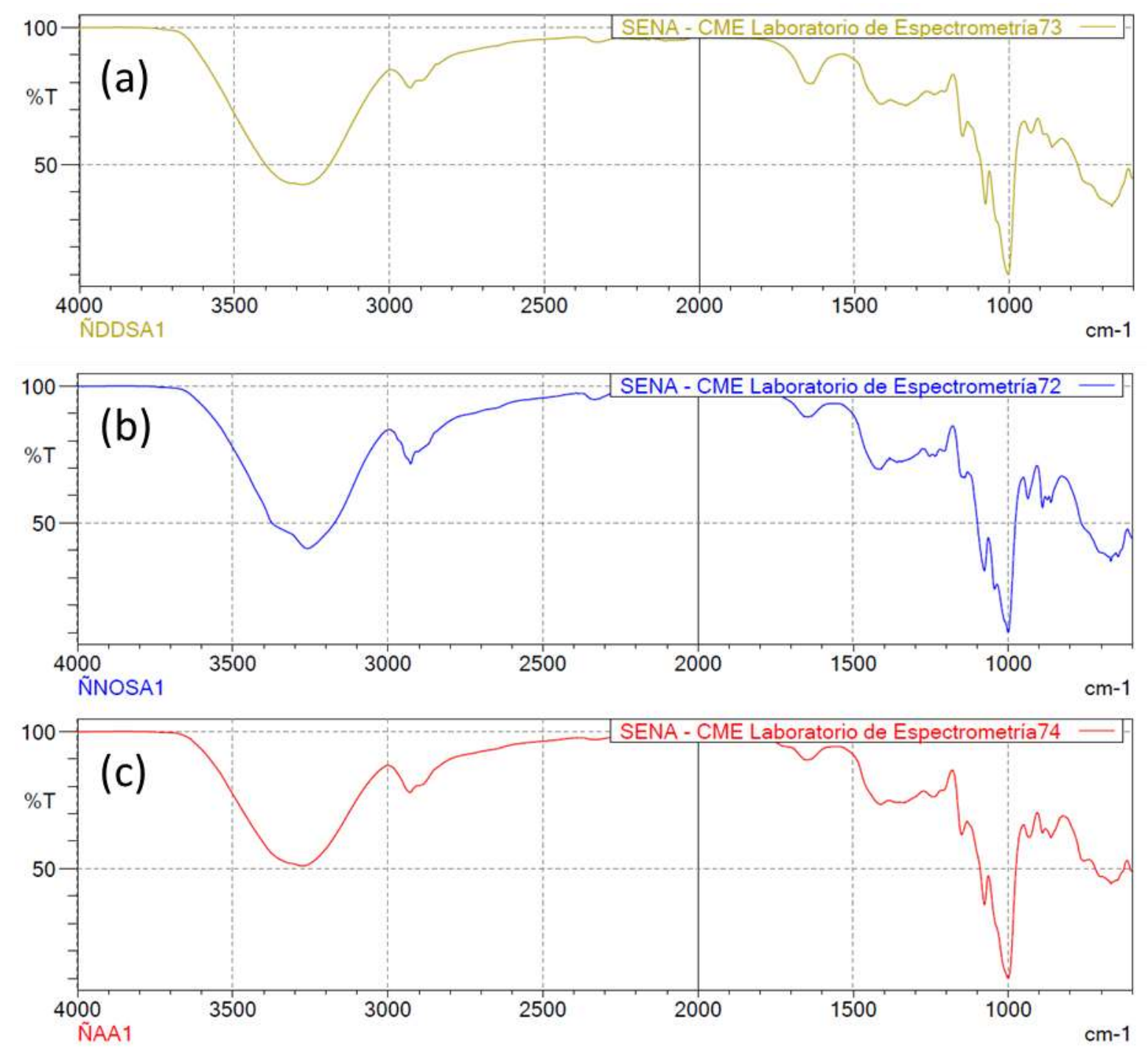

Figure 7. FTIR spectra of films based on Cassava starch: (a)esterified with DDSA, (b) esterified with OSA and (c) esterified AA.

\section{Conclusions}

Infrared Fourier transform spectroscopy revealed that those starches esterified dodecenil anhydride with succinic (DDSA), octenil anhydride (OSA) succinic and acetic anhydride (AA) suffered structural changes regarding the starches native and hydrolysates. However, in the films based on modified starches there is no variation in the FTIR spectrum, which is attributed to the low degree of substitution in the esterification process.

\section{Acknowledgments}

The authors are grateful to the Servicio Nacional de Aprendizaje (SENA) by funding applied research project entitled: development of active biofilm for food packaging based on yuca, sweet potato and Yam starch modified with Nanomaterials and the University of Cartagena to provide laboratories and equipment to undertake this research.

\section{References}

1. Gobernación de bolívar, PROYECTO DE ORDENANZA. Colombia. 2016, pp. 1-506.

2. O. V. López, L. A. Castillo, M. A. García, M. A. Villar, and S. E. Barbosa, (2015). Food packaging bags 
based on thermoplastic corn starch reinforced with talc nanoparticles. Food Hydrocolloids, 43, 18-24.

3. Meira, S. M. M., Zehetmeyer, G., Werner, J. O., \& Brandelli, A. (2017). A novel active packaging material based on starch-halloysite nanocomposites incorporating antimicrobial peptides. Food Hydrocolloids, 63, 561-570. doi:10.1016/j.foodhyd.2016.10.013.

4. Bet, C. D., Cordoba, L. P., Ribeiro, L. S., \& Schnitzler, E. (2017). Effect of acid modification on the thermal, morphological and pasting properties of starch from mango kernel (Mangifera indica L.) of Palmer variety. International Food Research Journal, 24(5), 1967-1974.

5. Jeong, O., \& Shin, M. (2018). Preparation and stability of resistant starch nanoparticles, using acid hydrolysis and cross-linking of waxy rice starch. Food Chemistry, 256, 77-84. doi:10.1016/j.foodchem.2018.02.098.

6. Dai, L., Li, C., Zhang, J., \& Cheng, F. (2018). Preparation and characterization of starch nanocrystals combining ball milling with acid hydrolysis. Carbohydrate Polymers, 180, 122-127. doi:10.1016/j.carbpol.2017.10.015.

7. Chen, P., Xie, F., Zhao, L., Qiao, Q., \& Liu, X. (2017). Effect of acid hydrolysis on the multi-scale structure change of starch with different amylose content. Food Hydrocolloids, 69, 359-368. doi:10.1016/j.foodhyd.2017.03.003.

8. Sun, Y., Gu, J., Tan, H., Zhang, Y., \& Huo, P. (2018). Physicochemical properties of starch adhesives enhanced by esterification modification with dodecenyl succinic anhydride. International Journal of Biological Macromolecules, 112, 1257-1263. doi:10.1016/j.ijbiomac.2018.01.222.

9. Fonseca-Florido, H. A., Vázquez-García, H. G., Méndez-Montealvo, G., Basilio-Cortés, U. A., NavarroCortés, R., Rodríguez-Marín, M. L., . . ., \& Gómez-Aldapa, C. A. (2018). Effect of acid hydrolysis and OSA esterification of waxy cassava starch on emulsifying properties in Pickering-type emulsions. Lebensmittel-Wissenschaft + Technologie, 91, 258-264. doi:10.1016/j.1wt.2018.01.057.

10. Shah, A., Masoodi, F. A., Gani, A., \& Ashwar, B. A. (2017). Physicochemical, rheological and structural characterization of acetylated oat starches. Lebensmittel-Wissenschaft + Technologie, 80, 19-26. doi:10.1016/j.lwt.2017.01.072.

11. Oleyaei, S. A., Almasi, H., Ghanbarzadeh, B., \& Moayedi, A. A. (2016). Synergistic reinforcing effect of TiO2and montmorillonite on potato starch nanocomposite films: Thermal, mechanical and barrier properties. Carbohydrate Polymers, 152, 253-262. doi:10.1016/j.carbpol.2016.07.040.

12. Feng, M., Yu, L., Zhu, P., Zhou, X., Liu, H., Yang, Y., . . ., \& Chen, P. (2018). Development and preparation of active starch films carrying tea polyphenol. Carbohydrate Polymers, 196, 162-167. doi:10.1016/j.carbpol.2018.05.043.

13. Mantovan, J., Bersaneti, G. T., Faria-Tischer, P. C. S., Celligoi, M. A. P. C., \& Mali, S. (2018). Use of microbial levan in edible films based on cassava starch. Food Packaging and Shelf Life, 18, 31-36. doi:10.1016/j.fpsl.2018.08.003.

14. Moreno, O., Cárdenas, J., Atarés, L., \& Chiralt, A. (2017). Influence of starch oxidation on the functionality of starch-gelatin based active films. Carbohydrate Polymers, 178, 147-158. doi:10.1016/j.carbpol.2017.08.128.

15. Phuong, H., Vu, N., \& Lumdubwong, N. (2016). Starch behaviors and mechanical properties of starch blend films with different plasticizers. Carbohydrate Polymers, $\cdots, 112-120$.

16. Mohsenabadi, N., Rajaei, A., Tabatabaei, M., \& Mohsenifar, A. (2018). Physical and antimicrobial properties of starch-carboxy methyl cellulose fi $\mathrm{lm}$ containing rosemary essential oils encapsulated in chitosan nanogel. International Journal of Biological Macromolecules, 112, 148-155. doi:10.1016/j.ijbiomac.2018.01.034.

17. Araújo, A., Galvão, A., Silva F. C., Mendes, F., Oliveira, M., Barbosa, F., Sousa F. M., \& Bastos, M. (2018). Okra mucilage and corn starch bio-based film to be applied in food. Polymer Testing, 71. doi:10.1016/j.polymertesting.2018.09.010.

18. Ren, L., Yan, X., Zhou, J., Tong, J., \& Su, X. (2017). Influence of chitosan concentration on mechanical and barrier properties of corn starch/chitosan films. International Journal of Biological Macromolecules, 105, 1636-1643. doi:10.1016/j.ijbiomac.2017.02.008. 